\title{
PRINCIPIO CONSTITUCIONAL DA LEGALIDADE
}

Ismael de Oliveira Assis

Universidade do Oeste Paulista - UNOESTE, Curso de Direito, Presidente Prudente, SP. E-mail: oliverismael@hotmail.com

\section{RESUMO}

O Princípio da Legalidade é uma enorme conquista jurídica e social. A história tem frequentemente evidenciado inúmeros casos de abusos dos Poderes Públicos, é com o auxílio desse princípio que o autoritarismo e as arbitrariedades podem ser combatidos. O objetivo deste trabalho, é expor a importância desse axioma, bem como sua adoção preventiva contra eventuais injustiças do Estado. A metodologia usada foi o histórico- analítico e dedutivo legal, com uso de bibliografias variadas, doutrinas especificas da área abordada, legislação e uso de relevantes bibliografias temáticas. Conclui-se, portanto, que para haver controle Estatal, e proteção de direitos fundamentais, o princípio da legalidade é indispensável.

Palavras-chave: Princípio da legalidade. Constituição. Democracia. Lei formal. Atos equiparados.

\section{CONSTITUTIONAL PRINCIPLE OF LEGALITY}

\begin{abstract}
The Principle of Legality is a huge legal and social achievement. History has often shown innumerable cases of abuses of the Public Powers, and with the aid of this principle authoritarianism and arbitrariness can be fought. The objective of this work is to expose the importance of this axiom, as well as its preventive adoption against possible injustices of the State. The methodology used was the historical-analytical and legal deductive, with use of varied bibliographies, specific doctrines of the area approached, legislation and use of relevant thematic bibliographies. It is concluded, therefore, that in order to have State control, and protection of fundamental rights, the principle of legality is indispensable.
\end{abstract}

Keywords: Principle of legality. Constitution. Democracy. Formal law. Related acts. 


\section{INTRUDUÇÃO}

A sujeição do próprio Estado a lei escrita foi resultado de enorme processo evolutivo. Pois a princípio o próprio poder Estatal detinha sobre si amplos poderes, as consequências disso foram os enormes abusos frente aso direitos fundamentais. Hoje com o princípio da legalidade, não mais o estado é sujeito a suas próprias liberalidades, deve ele antes de mais nada. Se sujeitar a própria soberania popular, manifestada na forma da lei. A relevância desse trabalho é evidenciar de forma expositiva os efeitos benéficos do principio da legalidade, e seu poder de limitação estatal. 0 objetivo e tecer estudo e analise dedutiva, a fim de se averiguar os benefícios sociais da adoção do princípio da legalidade.

\section{METODOLOGIA}

A metodologia empregada foi a aplicação de ampla pesquisa doutrinaria sobre a disciplina, estudo de legislação, e pesquisa em literatura de caráter variado, porém com pertinência temática. O método utilizado foi o histórico analítico, e o dedutivo, para obter o melhor êxito e aproveitamento sobre o assunto.

\section{LIMITAÇÃO LEGAL}

Hodiernamente, em termos jurídicos, é por meio da lei escrita que a sociedade melhor se organiza. A própria lei democrática representa nada menos que os anseios da sociedade, segundo Tavares (2017. p. 67) pondera-se que:

o povo estabelece suas leis, suas próprias regras de convivência. Na Declaração de Direitos do Homem e do Cidadão, de 1789, ficou consignado eternamente, nos termos de seu art. 6o, que "A lei é a expressão da vontade geral. Todos os cidadãos têm o direito de concorrer pessoalmente, ou pelos seus representantes, à sua formação.

Nesse sentido a lei é fundamental para o controle e prevenção de possíveis arbitrariedades. É com ela que temos assegurado inúmeros direitos.

Mas isso nem sempre foi assim.

\section{ASPECTO HISTÓRICO DO PRINCIPIO DA LEGALIDADE}

$\mathrm{Na}$ época em que a norma não era necessariamente escrita, mas sim consuetudinária (costumeira), a simples manifestação volitiva do Soberano era o que ditava toda e qualquer regra aos súditos. Nesse período as inseguranças jurídicas e mais ainda, as injustiças eram muito presentes. As graves e injustas praticas Estatais trouxeram serias consequências sociais e como resultado das inumeras violações dos direitos mais básicos do ser humano, o povo se viu forçado a impor limites legais contra o Poder público, o que para nossos dias atuais representa grande avanço e desenvolvimento:

"O mais celebre desses pactos é a magna carta, que consubstancia o acordo entre João sem Terra e seus súditos revoltados, sobre direitos a serem respeitados pela coroa (1215)." (FILHO, 1995, p. 4).

Segundo o doutrinador Vasconcelos (2017, p. 221) o Princípio da Legalidade pode ser rastreado até a carta Magna de João sem-terra em 1215, e na Bill of Rigths. Não dá para negar que foi exatamente nesse momento supracitado que a lei se tornou expressão da vontade popular contra as injustiças Estatais. Cabe ressaltar também que muito embora a lei começasse a ser aplicada como forma de controle, demorou para se generalizar. No entanto seus fundamentos e suas contribuições se enraizaram de tal maneira que se fazem positivamente presente nos dias atuais. 


\section{REVOLUÇÃO FRANCESA (1789)}

Conforme doutrina Barcellos (2018, P. 26), foi a própria Revolução Francesa de 1789 que se tornou símbolo supremo da luta pela liberdade, pois nela esteve fincado ideais de luta contra o absolutismo em favor primazia da legalidade e igualdade formal. De acordo com Lenza (2016, p. 84) pondera-se:

A ideia de que todo Estado deva possuir uma Constituição e de que esta deve conter limitações ao poder autoritário e regras de prevalência dos direitos fundamentais desenvolve-se no sentido da consagração de um Estado Democrático de Direito (art. 1.ํ, caput, da CF/88) e, portanto, de soberania popular.

A partir desse momento em diante toda ideologia humanizada e racional a respeito do princípio da legalidade foi se espalhando mundo afora, passando a partir de então a ser uma espécie de padrão para manutenção dos direitos fundamentais.

\section{DECLARAÇÃO DOS DIREITOS DO HOMEM E DO CIDADÃO (1789)}

A própria Declaração dos Direitos do Homem e do Cidadão, que rompeu com o antigo regime, e iniciou a uma nova era, expõe em seu artigo:

Art. 4. - A liberdade consiste em poder fazer tudo o que não prejudique o próximo: assim, o exercício dos direitos naturais de cada homem não tem por limites senão aqueles que asseguram aos outros membros da sociedade o gozo dos mesmos direitos. Estes limites só podem ser determinados pela lei.

O texto da declaração dos direitos do homem e do cidadão, em termos resumidos expõe o principio da legalidade com grande maestria.

\section{CONSTITUIÇÃO FEDERAL DE 1988}

Conceito de Constituição: Conforme doutrina Moraes (2016 p. 58), a própria definição de constituição tem seu sentido lato e sentido estrito, ou seja, jurídico. No sentido lato sensu do termo, constituição é o ato de construir, de afirmar, estabelecer, ou o modo como se constitui um grupo de pessoas, tendo assim uma, conotação de organização. Já no sentido jurídico da palavra, o autor expõe que o termo Constituição tem o conceito de lei fundamental e suprema de um Estado.

Ou seja, é dela que todo ordenamento retira sua força, e o padrão à ser seguido e obedecido, como um guia de direção.

\section{DEMOCRACIA E PRINCIPIO DA LEGALIDADE}

De acordo com Bahia (2017, p. 117), avalia-se que:

O Estado democrático de direito (art. 10 caput) repousa sob o signo da legalidade[...]. 0 princípio da legalidade, portanto, expressa a sujeição ou subordinação das pessoas, órgão ou entidades às prescrições emanadas do Legislativo, executivo e judiciário.

O Autoritarismo do Estatal, não deu certo. Para a melhor transparência e proteção de diretos inerentes ao homem foi preciso restringir e definir as funções do Poder Público. O escudo de defesa usado pelo povo contra o próprio Estado não foi nada menos do que a própria lei.

Em um primeiro momento, é compreensível que a imposição de obediência ao Estado significou forte ameaça a soberania da época, já que a estrutura soberana precisou se reestruturar e familiarizar com a subordinação legal. 


\section{PRINCIPIO DA LEGALIDADE (CF art. 5.ㅇ, II.)}

Segundo Souza (2003, p. 279) trata-se de "Princípio de ordem Constitucional, segundo o qual "Ninguém será obrigado a fazer ou deixar de fazer alguma coisa senão em virtude de lei" (art.5으. II- CF) [...]". De modo prático é a própria lei Estatal que contendo ordem de comando obrigatório delimita o próprio poder Público.

Moraes (2016, p. 106) preleciona que esse princípio objetiva combater o poder injusto do Estado, dizendo que o povo só está obrigado pela lei, e esta deve ser devidamente elaborada pelo processo legislativo constitucional.

\section{A LEI FORMAL E ATOS EQUIPARADOS}

Digno de nota é a posição de Vasconcelos (2017, p. 221-222) que expõe dizendo que somente a lei pode criar vinculo de obrigação, ou seja, é pela lei que surge a obrigação de fazer, ou não fazer. Nesse sentido quando existe a falta de lei, será permitido qualquer conduta de fazer ou não fazer. Em termos simples o princípio da legalidade diz somente respeito a lei formal, e os equiparados a leis formais.

Na definição de Vasconcelos (2017) a lei formal é aquela emanada do poder legislativo que respeita as formalidades de processo de sua elaboração.

Já os atos equiparados às leis formais, são aqueles elaboradas pelo Poder Executivo, no caso em questão são as leis delegadas e medidas provisórias.

Dessa maneira o princípio da legalidade constitucional se refere ordinariamente ao poder legislativo e excepcionalmente ao poder executivo. As normas infraconstitucionais segundo o supracitado autor, não atendem ao comando constitucional, sendo assim, na relação privada a conduta devera não contrariar a lei.

\section{AO PARTICULAR}

\section{PRINCÍPIO DA LEGALIDADE EM SENTIDO AMPLO}

Nas relações privadas, esse princípio atua mais como uma garantia, as partes poderão proceder conforme desejarem, desde que não ajam contra a lei. Nessa relação, predomina o princípio da autonomia da vontade.

"Para o particular, ninguém é obrigado a fazer ou deixar de fazer algo, senão em virtude de lei (aqui em sentido amplo ou material, referindo-se a qualquer espécie normativa), diante da sua autonomia da vontade." (Flavia Bahia. 2017, p. 117).

Embora a lei não restrinja severamente o particular nas relações privadas, como acontece em relação ao Estado, a conduta dos particulares não deve contradizer a legislação, devendo ser sempre pautado pela lei.

\section{ADMINISTRAÇÃO PUBLICA (art. 37 CAPUT , e art. 84. CF) PRINCÍPIO DA LEGALIDADE EM SENTIDO ESTRITO}

O próprio art. 37 caput da Constituição Federal de 1988 embasada no princípio da legalidade em face da Administração Pública determina: "A administração pública direta e indireta de qualquer dos Poderes da União, dos Estados, do Distrito Federal e dos Municípios obedecerá aos princípios de legalidade, impessoalidade, moralidade, publicidade e eficiência e, também, ao seguinte".

Em suma o princípio da legalidade surgiu opondo-se a qualquer forma antidemocrática, e poder arbitrário. Quanto a administração Pública, esta deverá ser orientada pelo o princípio da legalidade em sentido estrito, pois a administração só pode fazer o que a lei autoriza ou determina. Como o axioma tem como objetivo primário restringir as arbitrariedades do Estado, nas relações dos particulares essa restrição é mais frouxa, trata-se da legalidade ampla onde as partes podem fazer tudo quanto quiserem, com exceção se for proibido por lei (LENZA, 2016). 
É tão evidente de que a administração Pública deve somente se guiar em lei, que na previsão constitucional a administração pública se sujeita a lei:

Art. 84, IV: Compete privativamente ao Presidente da República sancionar, promulgar e fazer publicar as leis, bem como expedir decretos e regulamentos para sua fiel execução.

\section{PRINCIPIO DA LEGALIDADE NO DIREITO PENAL}

Tamanha é a importância do principio da legalidade, que além de das demais disciplinas do direito, esse principio foi também previsto no Direito Penal.

O emérito doutrinador Greco (2017 p.174) ao ensinar sobre o tema, preleciona que o princípio da legalidade é o mais importante princípio do Direito Penal.

É interessante notar também que a própria constituição contem em si, dispositivo que trata de assunto penal, e a esse respeito, fica exposto no inciso XXXIX do art. 5ㅇ da Constituição Federal, que diz: Não há crime sem lei anterior que o defina, nem pena sem prévia cominação legal.

Ou seja, trata a Lei fundamental de prever limitações ao Estado em matéria Penal, onde só poderá haver em regra alguma pena se antes houver uma lei com sua respectiva sanção.

O próprio Código Penal também expõe em seu artigo Art. 1ㅇ - Não há crime sem lei anterior que o defina. Não há pena sem prévia cominação legal.

Esse é um claro exemplo de princípio da legalidade no Direito Penal. Além dos demais supracitado. Com isso não resta nenhuma duvida de que o principio constitucional da legalidade, é imensa aquisição para todo corpo social, uma vez que mediante ela, temos garantias de respeito aos direito fundamentais, que são essenciais para a vida.

\section{CONCLUSÃO}

Portanto fica evidente que o princípio da legalidade é um avanço jurídico, no sentido de que contribui e muito para a manutenção de direito fundamentais. . Ainda hoje não existe meio de controle do poder publico mais eficaz do que a lei. A adesão e incorporação desse principio na Constituição Federal, objetiva não somente o controle Estatal, mas também dar ciência a toda população dos limites legais a respeito do que é permitido e do que é proibido, de modo que tal conhecimento possibilita também a certeza de poder procurar tutela jurisdicional quando do acometimento de arbitrariedades do próprio Estado. Portanto ficou claro que sem o supramencionado princípio, pouca eu nenhuma garantia teríamos de resguardo de princípios e direitos fundamentais.

\section{REFERENCIAS}

BAHIA, F. Direito constitucional: coleção descomplicando. 3.ed. Pernambuco: Armador, 2017.

BARCELLOS, A. Curso de direito constitucional. Rio de Janeiro: Forense, 2018.

FILHO, M. Curso de direito constitucional. 22. ed. São Paul: Saraiva, 1995.

VASCONCELOS, C. Curso de direito constitucional. 4. ed. São Paulo: Saraiva, 2017.

GRECO, R. curso de direito penal: parte geral. 19.ed. Rio de Janeiro: Impetus, 2017.

LENZA, P. Direito constitucional esquematizado. 20. ed. São Paulo: Saraiva, 2016.

MORAES, A. Direito constitucional. 32. ed. São Paulo: Atlas, 2016. 
TAVARES, A. Curso de direito constitucional. 15. ed. São Paulo: Saraiva, 2017.

SOUZA, A. Dicionário técnico - jurídico de bolso. São Paulo: Gion, 2003. 